\title{
Endovascular Treatment of Unruptured MCA Bifurcation Aneurysms Regardless of Aneurysm Morphology: Short- and Long-Term Follow-Up
}

\author{
(D)F. Hagen, (DC.J. Maurer, and (D) A. Berlis
}

\begin{abstract}
BACKGROUND AND PURPOSE: The optimal treatment of unruptured middle cerebral aneurysms is still under debate. Although today almost any aneurysm can be treated endovascularly, there is a lack of data comparing endovascular and microsurgical repair of MCA aneurysms. The aim of our analysis is to provide data on the efficacy, clinical outcome, complications and re-treatment rates of endovascular treatment of this subtype of aneurysms.
\end{abstract}

MATERIALS AND METHODS: Between May 2008 and July 2017, endovascular treatment of 1184 aneurysms in 827 patients was performed in our department. Twenty-four percent of these aneurysms were located at the MCA, and 150 unruptured MCA bifurcation aneurysms treated with coiling, stent-assisted-coiling, or endovascular flow diverter (WEB device) were identified for this retrospective data analysis. Ninety-six percent of all aneurysms, ruptured and unruptured, were treated by an endovascular approach, which yields a low selection bias for aneurysms suitable for endovascular treatment. Follow-up examinations were performed after 12 and 36 months and then every 1-3 years after embolization. Procedures were analyzed for periprocedural complications, outcome, and retreatment rate of the WEB $(n=38)$ and coiling with $(n=45)$ or without stent assistance $(n=67)$.

RESULTS: The procedure-associated good clinical outcome (mRS $\leqq 2$ ) was $89.9 \%$, and the mortality rate was $2.7 \%$. Short-term follow-up good clinical outcome/mortality rates were $91.3 \% / 0.7 \%$. At discharge, 137 patients had an mRS of 0-2 (91.3\%) and 13 had an mRS of 3-6 (8.7\%). The retreatment rate was significantly higher in the WEB group (21.1\%) compared with the coiling group with (5.9\%) or without (2.2\%) stent placement $(P<.05)$.

CONCLUSIONS: Regardless of the architecture of MCA bifurcation aneurysms, the endovascular treatment can be performed with low morbidity/mortality rates. The higher retreatment rate in the WEB group correlates with the learning curve in choosing the right device size.

ABBREVIATION: ASA = acetylsalicylic acid

S ince the publication of the results of the International Subarachnoid Aneurysm Trial (ISAT), in 2002, endovascular treatment of ruptured intracranial aneurysms has been regarded as the treatment of choice. ${ }^{1}$ Later, the International Study of Unruptured Intracranial Aneurysms confirmed that the treatment of unruptured aneurysms is feasible by endovascular treatment as well. ${ }^{2}$ Because MCA aneurysms were underrepresented in the ISAT study, debate remains about the best way to treat these aneurysms, whether ruptured or not. Additionally, a prospective randomized study of the treatment of unruptured aneurysms,

Received September 23, 2018; accepted after revision January 4, 2019.

From the Department of Diagnostic and Interventional Neuroradiology, Klinikum Augsburg, Augsburg, Germany.

Please address correspondence to C.J. Maurer, MD, Klinikum Augsburg, Stenglinstr. 2, 86156 Augsburg, Germany; e-mail:

christoph.maurer@klinikum-augsburg.de

http://dx.doi.org/10.3174/ajnr.A5977 which objectively evaluates outcomes, does not exist, to our knowledge.

To date, microsurgical clipping of unruptured middle cerebral artery aneurysms is the treatment of choice. One reason in favor of clipping versus coiling is that the use of additional devices such as microstents requires platelet inhibition, which can lead to longterm complications. Recent publications demonstrate good clinical outcomes and low complication rates for both methods. ${ }^{3,4}$

An essential point is that when we compared the 2 methods, the investigation objective is the same. Therefore, we present our endovascular treatment data of MCA bifurcation aneurysms from 2 hospitals (Klinikum Augsburg and Schoen Klinik, Vogtareuth, Germany). The treatment in both hospitals was performed by the neurointerventionalists from Klinikum Augsburg, since our neurointerventional department has a cooperation with the Schoen Klinik in Vogtareuth. Because in our setting almost all aneurysms (>96\%), ruptured or not, were treated by endovascular means, there is a low 


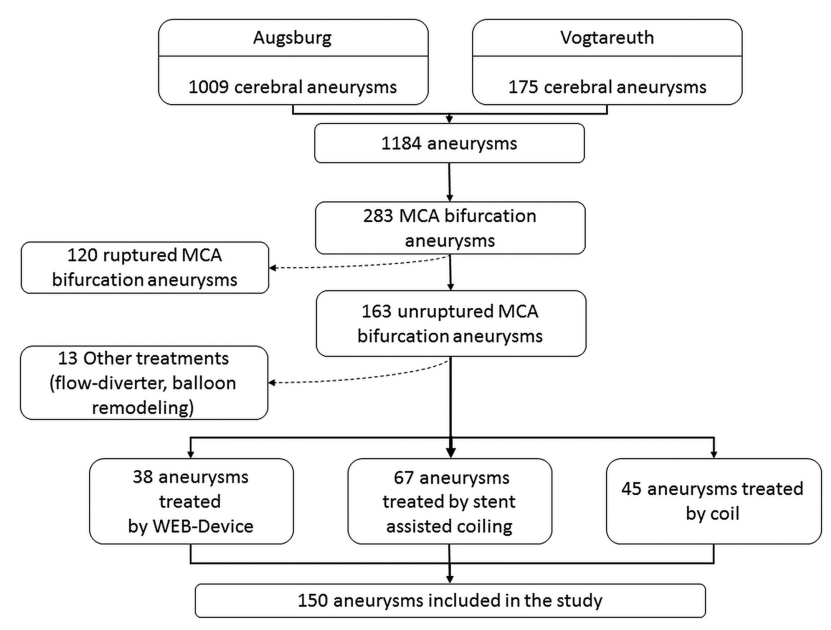

FIG 1. Study design.

selection bias for aneurysms suitable for endovascular therapy. We present our real-world data of endovascular treatment of MCA aneurysms during a 9-year period using coils, stent-assisted coiling, and an endosaccular flow diverter (Woven EndoBridge, WEB; Sequent Medical, Aliso Viejo, California). Specifically, the WEB device was designed to effectively treat wide-neck, symmetric, cylindriform, or spheric aneurysms by an endovascular approach.

Additionally, the aim of our analysis was to evaluate whether the use of the WEB versus coils may shorten the intervention time and improve the outcome with regard to long-term occlusion and/or the retreatment rate.

\section{MATERIALS AND METHODS}

In this retrospective analysis, patients treated for an unruptured bifurcation aneurysm of the middle cerebral artery between May 2008 and July 2017 were included. A total of 1184 aneurysms in 827 patients had been treated by an endovascular technique during this time in our institution. This number corresponds to $96 \%$ of all aneurysms treated in both centers during this period. The other $4 \%$, corresponding to 50 aneurysms (12 MCA aneurysms), were patients with intracerebral hemorrhage and emergency evacuation of space-occupying parenchymal hemorrhage and simultaneous clipping of the aneurysms. In elective cases, the patient's choice of clipping was the reason for nonendovascular treatment. There was no treatment failure or crossover from endovascular therapy to clipping.

About 24\% (242/1009 in Augsburg and 42/175 in Vogtareuth) of all endovascularly treated aneurysms were located at the MCA bifurcation. All patients were treated by neuroradiologists from the neuroradiology department of Augsburg (Germany) (Fig 1).

Aneurysms were qualified as the coil group if they had been treated by coils or by stent-assisted coiling. Aneurysms were included to the WEB group if $\geq 1$ WEB device had been used. Patients treated with other devices such as flow diverters or remodeling balloons were excluded due to the low number, as well as aneurysms that were not located at the MCA bifurcation such as the proximal M1 or distal M2-M4 segments. According to our follow-up protocol, 3-6 months after treatment a combination of MR imaging and MR angiography, including TOF and contrast-enhanced MRA (Avanto/ Aera, 1.5T for both; Siemens, Erlangen, Germany) and/or conven- tional digital subtraction angiography (biplane Artis zee, Siemens; or biplane Allura Xper FD20/20, Philips Healthcare, Best, the Netherlands), was performed. If no treatment was necessary, standard follow-up imaging consisted of MR imaging and MRA 18 months, 3 years, and 5 years after treatment.

\section{Aneurysm Treatment}

Total treatment time includes the period from general anesthesia to extubation of the patient, including complete diagnostic angiography of all cerebral supplying vessels. Heparin (5000 IU IV) was given immediately before the start of endovascular treatment to prevent thromboembolic events. Most of the patients were pretreated 5 days before the procedure with double antiaggregation with aspirin (ASA) (100 mg) and an adenosine-diphosphate receptor inhibitor (clopidogrel, $75 \mathrm{mg}$ ). The day before treatment, platelet inhibition was tested using the Multiplate Analyzer (Roche Diagnostics, Mannheim, Germany). Patients with an insufficient platelet inhibition by clopidogrel in the Multiplate Analyzer test received a loading dose of ticagrelor $(180 \mathrm{mg})$ followed by ticagrelor ( $90 \mathrm{mg}$ ) 2 times daily.

\section{Retreatment}

If relevant recanalization was detected at follow-up imaging, a retreatment strategy was proposed to our patients. All of them accepted endovascular retreatment.

\section{Complications}

The electronic medical files were screened for complications related to the intervention, such as vessel dissections, thromboembolic events, vasospasms, hemorrhages, and infarctions, as well as mRS, death on discharge, and follow-up.

\section{Statistical Analysis}

Statistical analysis was performed using SPSS (Release 22.0.0; IBM, Armonk, New York). Analyses included descriptive statistics, $\chi^{2}$ and Fisher exact tests, and the Kruskal-Wallis H test with 3 independent samples. Graphics were designed by Excel 2017 (Microsoft, Redmond, Washington).

According to the guidelines of the local ethics committee, no further approval was necessary for this retrospective analysis.

\section{RESULTS}

We included 150 unruptured aneurysms at the MCA bifurcation in our final analysis. Thirty-eight aneurysms were treated by WEB devices, and 112 aneurysms, by coiling or stent-assisted coiling. In the coiling group, 45 aneurysms were treated by coils alone and 67 aneurysms were treated by stent-assisted coiling using $1(n=55)$ or $>1$ self-expanding microstent $(n=12)$. There was no significant difference in the distribution of age, sex, and comorbidities such as arterial hypertension, diabetes, or smoking (Table 1).

All treated aneurysms were $<25 \mathrm{~mm}$. Aneurysm size was significantly larger in the WEB group. Fifty percent of all aneurysms in the WEB group measured between 8 and $15 \mathrm{~mm}$, whereas in the coil group, only $25 \%$ were $>7 \mathrm{~mm}$. Accordingly, the mean neck size in the WEB group $(4.46 \pm 1.26 \mathrm{~mm})$ was larger than that in the coiling group $(2.90 \pm 1.00 \mathrm{~mm})$ and in the stent-assisted coiling group $(3.9 \pm 1.5 \mathrm{~mm})(P<.05)$ (Table 2$)$. 
Table 1: Demographic data

\begin{tabular}{|c|c|c|c|c|}
\hline & \multicolumn{2}{|c|}{ Coil Group } & \multirow[b]{2}{*}{$\begin{array}{l}\text { WEB } \\
\text { Group } \\
(n=38)\end{array}$} & \multirow[b]{2}{*}{ Significanc } \\
\hline & $\begin{array}{l}\text { Coiling } \\
(n=45)\end{array}$ & $\begin{array}{c}\text { Stent-Assisted } \\
\text { Coiling } \\
(n=67)\end{array}$ & & \\
\hline Age (mean) (yr) & $54.6 \pm 10.5$ & $55.7 \pm 10.8$ & $59.8 \pm 11.7$ & $.071^{\mathrm{a}}$ \\
\hline \multicolumn{5}{|l|}{$\operatorname{Sex}(\mathrm{No})}$. \\
\hline Male & $12(26.7 \%)$ & $17(25.4 \%)$ & $13(34.2 \%)$ & $.638^{\mathrm{b}}$ \\
\hline Female & $33(73.3 \%)$ & $50(74.6 \%)$ & $25(65.8 \%)$ & \\
\hline Hypertension (No.) & $24(53.3 \%)$ & $38(65.7 \%)$ & $25(65.8 \%)$ & $.497^{\mathrm{b}}$ \\
\hline Diabetes (No.) & $1(2.2 \%)$ & $7(10.4 \%)$ & $2(5.3 \%)$ & $.254^{\mathrm{b}}$ \\
\hline Smoker (No.) & $16(35.6 \%)$ & $30(44.8 \%)$ & $17(44.3 \%)$ & $.611^{\mathrm{b}}$ \\
\hline
\end{tabular}

${ }^{a}$ Kruskal-Wallis $\mathrm{H}$ test.

${ }^{\mathrm{b}}$ Fisher exact test.

Table 2: Aneurysm characteristics

\begin{tabular}{|c|c|c|c|c|}
\hline & \multicolumn{2}{|c|}{ Coil Group } & \multirow[b]{2}{*}{$\begin{array}{c}\text { WEB } \\
\text { Group } \\
(n=38)\end{array}$} & \multirow[b]{2}{*}{ Significance } \\
\hline & $\begin{array}{l}\text { Coiling } \\
(n=45)\end{array}$ & $\begin{array}{c}\text { Stent-Assisted } \\
\text { Coiling } \\
(n=67)\end{array}$ & & \\
\hline \multicolumn{5}{|l|}{ Aneurysm size (No.) } \\
\hline $0-7 \mathrm{~mm}$ & $37(82.2 \%)$ & $47(70.1 \%)$ & $19(50.0 \%)$ & $.014^{\mathrm{a}}$ \\
\hline $8-15 \mathrm{~mm}$ & $7(15.6 \%)$ & $16(23.9 \%)$ & $19(50.0 \%)$ & \\
\hline $16-25 \mathrm{~mm}$ & $1(2.2 \%)$ & $4(6.0 \%)$ & $0(0.0 \%)$ & \\
\hline$>25 \mathrm{~mm}$ & $0(0.0 \%)$ & $0(0.0 \%)$ & $0(0.0 \%)$ & \\
\hline Aneurysm neck (mean) (mm) & $2.9 \pm 1.0$ & $3.9 \pm 1.5$ & $4.46 \pm 1.26$ & $.000^{\mathrm{b}}$ \\
\hline Aspect ratio (dome/neck) (mean) & $3.29 \pm 1.48$ & $2.60 \pm 0.98$ & $2.55 \pm 1.00$ & $.005^{\mathrm{b}}$ \\
\hline \multicolumn{5}{|l|}{ Side (No.) } \\
\hline Right & $20(44.4 \%)$ & $36(53.7 \%)$ & 27 (71.1\%) & $.050^{\mathrm{b}}$ \\
\hline Left & $25(55.6 \%)$ & $31(46.3 \%)$ & $11(28.9 \%)$ & \\
\hline Partially thrombosed (No.) & $2(4.4 \%)$ & $2(3.0 \%)$ & $3(7.8 \%)$ & $1.000^{c}$ \\
\hline
\end{tabular}

Table 3: Procedural and related complications

\begin{tabular}{|c|c|c|c|c|}
\hline & \multicolumn{2}{|c|}{ Coil Group } & \multirow[b]{2}{*}{$\begin{array}{c}\text { WEB } \\
\text { Group } \\
(n=38)\end{array}$} & \multirow[b]{2}{*}{ Significance } \\
\hline & $\begin{array}{l}\text { Coiling } \\
(n=45)\end{array}$ & $\begin{array}{c}\text { Stent-Assisted } \\
\text { Coiling } \\
(n=67)\end{array}$ & & \\
\hline Procedural time (mean) (min) & $155.5 \pm 68.2$ & $165.1 \pm 54.3$ & $136.3 \pm 55.8$ & $.018^{\mathrm{a}}$ \\
\hline $\begin{array}{l}\text { Total device per aneurysm } \\
\text { implanted (mean) }\end{array}$ & $3.8 \pm 2.4$ & $7.3 \pm 5.8$ & $1.0 \pm 0.0$ & $.000^{\mathrm{a}}$ \\
\hline $\begin{array}{l}\text { Complication rate (No.) } \\
\text { according to Table } 4\end{array}$ & $3(6.7 \%)$ & $5(7.4 \%)$ & $3(7.9 \%)$ & $1.000^{\mathrm{b}}$ \\
\hline
\end{tabular}

The procedural time differed significantly in the 3 groups (136.3 $\pm 55.8 \mathrm{~min}$ utes in the WEB group versus $155.5 \pm 68.2$ minutes in the coiling group versus $165.1 \pm 54.3$ minutes in the stent-assisted coiling group; Table 3 and Fig 2). A total of 578 coils and 85 stents (Neuroform 3, Neuroform Atlas, Stryker Neurovascular, Kalamazoo, Michigan; and LVIS Jr, MicroVention, Tustin, California) were used in the treatment of the MCA bifurcation aneurysms.

Seven Multiplate Analyzer tests were missing in the electronic medical files. Eleven complications occurred during or immediately after the intervention. Seven (63.6\%) were thromboembolic events, 3 of which occurred despite double antiaggregation and a sufficient platelet inhibition as tested by the Multiplate Analyzer. One infarction without thrombus detection during angiography occurred despite positive findings on the Multiplate Analyzer test. Two MCA ruptures and 1 hemodynamically relevant vasospasm took place in the coil group. No significant differences were found in the clinical outcome indicated by the modified Rankin Scale on discharge or in the complication rate (Table 4). The mRS at discharge had mean values of 0.66 (WEB), 1.50 (coils), and 4.25 (stent-assisted coiling) in the 11 patients with procedure-related complications (Table 4).

The mean follow-up period was $22.3 \pm 16.7$ months in the WEB group, $38.9 \pm 26.8$ months for the coiling group, and $29.9 \pm 23.4$ months for the stent-assisted coiling group $(P=.024)$. A significantly higher reintervention rate in the WEB group was noticed; $21.1 \%$ of the aneurysms had to be retreated in the WEB group compared with $4.5 \%$ in the coil

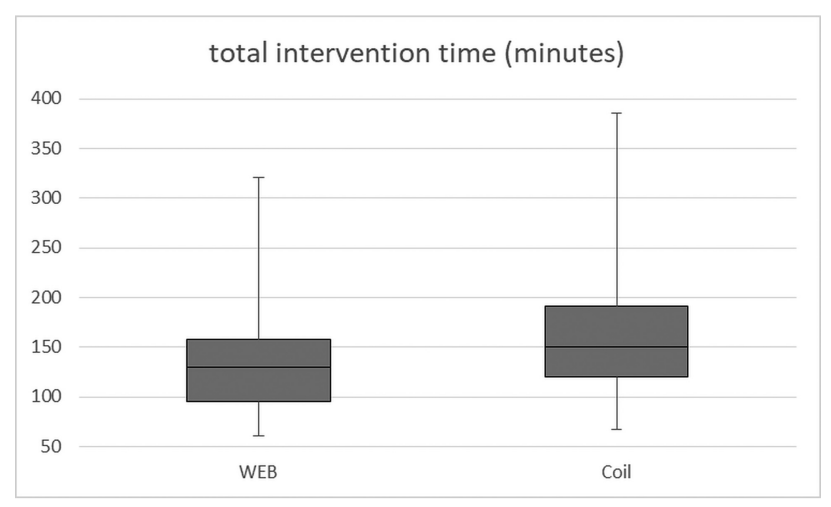

FIG 2. Total intervention time by technique. group $(P=.002)$. Twelve incompletely treated aneurysms were detected 6 months after the intervention. One aneurysm was detected and retreated after 24 months. At discharge, 126 patients had an mRS of 0 (84\%); 11, an mRS of 1-2 (7.3\%); and 13, an mRS of 3-6 $(8.7 \%)$. No statistical significance was found for delay of the procedure, $\mathrm{mRS}$ at discharge, or the long-term mRS scores among the 3 groups. A significant difference was found for the follow-up period and retreatment rate (Table 5).

Thirteen aneurysms were retreated after an endovascular intervention; 8 aneurysms, after a WEB device employment; and 5 aneurysms, after coiling or stent-assisted coiling. The mean neck size was $4.35 \pm 1.97 \mathrm{~mm}$ in the coil-group and $5.38 \pm 1.14 \mathrm{~mm}$ in the WEB group (Table 6).

Thirty-eight unruptured MCA bifurcation aneurysms were 


\begin{tabular}{|c|c|c|c|c|c|}
\hline Patient No. & Complication & $\begin{array}{l}\text { Hospitalization } \\
\text { Time (days) }\end{array}$ & $\begin{array}{c}\mathrm{mRS} \text { at } \\
\text { Discharge }\end{array}$ & $\begin{array}{c}\mathrm{mRS} \\
\text { Long-Term/months }\end{array}$ & Antiaggregation \\
\hline \multicolumn{6}{|l|}{ WEB group } \\
\hline 65 & Ischemia due to local thrombus & 8 & 0 & $0 / 12$ & Simple \\
\hline 92 & Occlusion of external iliac artery & 9 & 0 & $3 / 48$ & Simple \\
\hline 121 & Ischemia due to local thrombus & 2 & 2 & $1 / 6$ & Simple \\
\hline \multicolumn{6}{|l|}{ Coil group } \\
\hline \multicolumn{6}{|l|}{ Coiling } \\
\hline 6 & Aneurysm rupture & 17 & 0 & $0 / 36$ & Simple \\
\hline 37 & Ischemia due to local thrombus & 11 & 3 & $2 / 12$ & Double \\
\hline 179 & Ischemia due to local thrombus & 4 & 0 & $1 / 3$ & Simple \\
\hline \multicolumn{6}{|c|}{ Stent-assisted coiling } \\
\hline 36 & Ischemia due to local thrombus & 11 & 3 & $2 / 12$ & Double \\
\hline 45 & Aneurysm rupture & 24 & 6 & - & Double \\
\hline 99 & Infarction without thrombus detection & 8 & 4 & $3 / 12$ & Double \\
\hline 116 & Ischemia due to local thrombus & 8 & 4 & $4 / 36$ & Double \\
\hline 158 & Relevant vasospasm & 8 & 3 & $0 / 12$ & Double \\
\hline
\end{tabular}

Table 5: Follow-up and reintervention rate

\begin{tabular}{|c|c|c|c|c|}
\hline & \multicolumn{2}{|c|}{ Coil Group } & \multirow[b]{2}{*}{$\begin{array}{c}\text { WEB } \\
\text { Group }(n=38)\end{array}$} & \multirow[b]{2}{*}{ Significance } \\
\hline & $\begin{array}{l}\text { Coiling } \\
(n=45)\end{array}$ & $\begin{array}{l}\text { Stent-Assisted } \\
\text { Coiling }(n=67)\end{array}$ & & \\
\hline Follow-up-period (mean) (mo) & $38.9 \pm 26.8$ & $29.9 \pm 23.4$ & $22.3 \pm 16.7$ & $.024^{\mathrm{a}}$ \\
\hline Rate of retreatment (No.) & $1(2.2 \%)$ & $4(5.9 \%)$ & $8(21.1 \%)$ & $.014^{\mathrm{b}}$ \\
\hline Delay of retreatment after procedure (mean) (mo) & $12 \pm 0.0$ & $9.8 \pm 9.6$ & $4.5 \pm 1.6$ & $.187^{\mathrm{a}}$ \\
\hline mRS (discharge) (mean) & $0.3 \pm 0.8$ & $0.6 \pm 1.4$ & $0.2 \pm 0.6$ & $.283^{\mathrm{a}}$ \\
\hline Good clinical outcome at discharge (mRS $\leq 2)$ (No.) & $42(93.3 \%)$ & $58(86.6 \%)$ & $37(97.4 \%)$ & $.186^{\mathrm{b}}$ \\
\hline Death (No.) & 0 & 1 & 0 & $1.000^{\mathrm{b}}$ \\
\hline \multicolumn{5}{|l|}{ Clinical outcome (No.) } \\
\hline \multicolumn{5}{|l|}{ mRS at last follow-up (No.) } \\
\hline 0 & $33(84.6 \%)$ & $38(73.1 \%)$ & $32(88,9 \%)$ & \\
\hline 1 & $3(7.7 \%)$ & $2(3.9 \%)$ & $2(5.6 \%)$ & \\
\hline 2 & $1(2.6 \%)$ & $3(5.8 \%)$ & $0(0.0 \%)$ & $.164^{\mathrm{b}}$ \\
\hline $3-5$ & $1(2.6 \%)$ & $6(11.5 \%)$ & $2(5.6 \%)$ & \\
\hline 6 & $1(2.6 \%)$ & $3(5.8 \%)$ & $0(0.0 \%)$ & \\
\hline \multicolumn{5}{|l|}{ Follow-up period (No.) } \\
\hline mRS improvement or consistent & $34(87.2 \%)$ & 40 (77.0\%) & 33 (91.6\%) & \\
\hline mRS degradation & $5(12.8 \%)$ & $12(23.0 \%)$ & $3(8.3 \%)$ & $.109^{\mathrm{b}}$ \\
\hline
\end{tabular}

${ }^{a}$ Kruskal-Wallis $\mathrm{H}$ test.

${ }^{b}$ Fisher exact test.

Table 6: Characteristics of retreated aneurysms

\begin{tabular}{|c|c|c|c|c|}
\hline & \multicolumn{2}{|c|}{ Coil Group } & \multirow{2}{*}{$\begin{array}{l}\text { WEB } \\
\text { Group } \\
(n=8)\end{array}$} & \multirow[b]{2}{*}{ Significance } \\
\hline & $\begin{array}{l}\text { Coiling } \\
(n=1)\end{array}$ & $\begin{array}{c}\text { Stent-Assisted } \\
\text { Coiling }(n=4)\end{array}$ & & \\
\hline \multicolumn{5}{|l|}{ Aneurysm size (No.) } \\
\hline 0-7 mm & $1(100 \%)$ & $1(25 \%)$ & $2(25.0 \%)$ & $.734^{\mathrm{a}}$ \\
\hline $8-15 \mathrm{~mm}$ & $0(0.0 \%)$ & $2(50 \%)$ & $6(75.0 \%)$ & \\
\hline $16-25 \mathrm{~mm}$ & $0(0.0 \%)$ & $1(25 \%)$ & $0(0.0 \%)$ & \\
\hline$>25 \mathrm{~mm}$ & $0(0.0 \%)$ & $0(0.0 \%)$ & $0(0.0 \%)$ & \\
\hline \multicolumn{5}{|l|}{ Side (No.) } \\
\hline Right & $1(100 \%)$ & $4(100 \%)$ & $3(37,5 \%)$ & $.046^{\mathrm{b}}$ \\
\hline Left & $0(0 \%)$ & $0(0 \%)$ & $5(62,5 \%)$ & \\
\hline Aneurysm neck (mean) (mm) & $1.68 \pm 0.0$ & $5.03 \pm 1.49$ & $5.38 \pm 1.14$ & $.273^{\mathrm{c}}$ \\
\hline Aspect ratio (dome/neck) (mean) & $4.17 \pm 0.0$ & $3.25 \pm 2.01$ & $2.45 \pm 0.71$ & $.406^{c}$ \\
\hline
\end{tabular}

\section{DISCUSSION}

To our knowledge, this is the first study comparing the WEB device with coiling or stent-assisted coiling in a single center setting. We analyzed our data with regard to intervention time, follow-up (after discharge and long-term), and procedure-related complications to assess the effectiveness of endovascular treatment of aneurysms located at the MCA bifurcation. Approximately $25 \%$ of all aneurysms treated in Augsburg and Vogtareuth by endovascular means were MCA aneurysms. The incidence is consistent with the published literature of MCA aneurysms ranging from $14 \%$ to $29 \%$ of all aneurysms, depending on whether unruptured or ruptured aneurysms were included in the particular study. ${ }^{1,2}$ This finding shows that MCA bifurcation aneurysms were treated in our institution regardless of aneurysm treated between 2013 and July 2017 using the WEB device. The retreatment rate decreased continuously across the years from initially 50\% (2012) to $0 \%$ (2017) (Fig 3). 


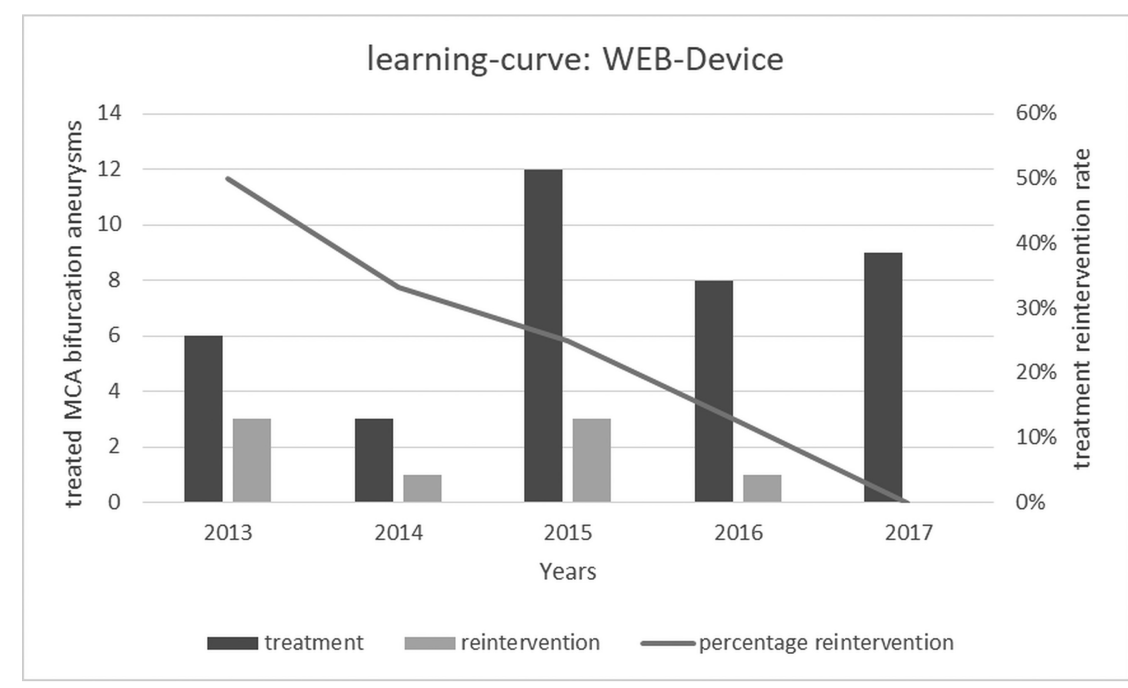

FIG 3. Retreatment rate of aneurysms treated with the WEB device (2013-2017). dez et $\mathrm{al}^{8}$ found a 2 times higher risk for such a complication during clipping compared with endovascular aneurysm repair $(3.4 \%$ versus $1.7 \%)$. With an intraprocedural rupture rate of $1.3 \%$, our data are comparable with these findings. The major complication in endovascular treatment is still a thromboembolic event. With a rate of $5.3 \%$, our data slightly exceeded the released findings (3.2\%) of Rodriguez-Hernandez et al. ${ }^{8}$

\section{Complications}

We found no significant difference in the complication rates between the WEB and the coil and the stent-assisted coiling groups. Overall, 11 periprocedural complications occurred in all 150 patients $(7.3 \%)$. Five events had a throm- morphology and vessel anatomy, leading to a treatment rate of $>96 \%$ of all intracranial aneurysms by an endovascular technique. The major reason for the nonendovascular approach, corresponding to 50 intracranial aneurysms (14 MCA aneurysms), was the necessity of decompression of a space-occupying intracranial hematoma or the explicit patient request. Hence, we have virtual no selection of the easily accessible aneurysms, which reduces the potential selection bias to a minimum.

\section{Comparison between Surgical Clipping and Endovascular Technique}

The proper treatment of intracranial aneurysms is still controversial. Only $66 \%$ of all unruptured aneurysms in Germany were treated by endovascular techniques, ${ }^{5}$ despite the results of the ISAT study 2002 and its recommendation of endovascular treatment. One point of criticism of endovascular aneurysm treatment is the higher reintervention rate compared with clipping. However, since the publication of ISAT, the stent design has significantly improved, allowing the use of stents in smaller vessels; new devices such as intra- and extrasaccular flow diverters have appeared on the market; and finally, the coil structure has developed even further with softer coils and the introduction of bioactive coils such as HydroCoils (MicroVention). The higher packing density of HydroCoils seems to be translated into a lower reintervention rate compared with first-generation coils. ${ }^{6}$

With a total mortality rate of $0.6 \%$ directly after discharge and $2.7 \%$ in long-term follow-up, our results are in the range of published outcomes. ${ }^{7}$ In direct comparison with surgical clipping, the mortality rate after the endovascular technique was at least equal to recent published data $(1.9 \%-2.0 \%){ }^{8,9}$ We found a good clinical outcome ( $\mathrm{mRS} \leqq 2$ ) in $91.3 \%$ directly after discharge and in $89.8 \%$ after long-term follow-up. In their comparative analysis, McDonald et $\mathrm{al}^{7}$ found a similar in-hospital mortality risk, but in long-term follow-up, the outcome in surgical treatment was significantly worse than after endovascular technique. Compared with published surgical data of unruptured MCA aneurysms (mRS $\leqq 2$ in $92 \%),{ }^{8}$ our results seem to be comparable. Especially, intraprocedural aneurysm rupture is considered an important complication in clipping intervention. Rodriguez-Hernan- boembolic origin. Two aneurysms ruptured during the intervention, and 1 relevant vasospasm, 1 stent thrombosis, and 1 infarction occurred in the coil group. We had 8 complications in the coil group. In relation to the total coiled aneurysms $(n=112)$, this meant a $7.1 \%$ complication rate, which is much lower compared with other findings. ${ }^{9}$

Compared with the published literature on intrasaccular flow diverters, we had a lower complication rate after using the WEB device (7.9\% versus $11.8 \%) .{ }^{10}$ Thromboembolic events occurred twice after double antiaggregation with ASA, $100 \mathrm{mg}$, and clopidogrel, $75 \mathrm{mg}$, and 3 times after single antiaggregation with ASA, $100 \mathrm{mg}$, alone. There was a trend toward risk reduction, but it was not significant. ${ }^{11}$ However, when a complication occurred, the short-term mRS and the long-term mRS of the WEB-treated aneurysms ( $\mathrm{mRS}=0.67$ and 1.33 , respectively) were much lower than those in the coil-treated aneurysms ( $\mathrm{mRS}=2.88$ and 2.25). The outcome after coil and stent intervention, especially, caused grave complications compared with the single use of coils or a WEB device. This outcome is also reflected in the hospitalization time. The mean hospitalization time after the WEB device use was about 6 days compared with 11 days (coiling only) and 12 days (stent-assisted-coiling) (Table 4). However, the aneurysms treated by stent-assisted coiling were much larger than the aneurysms treated by coils alone. Furthermore, the average neck size was $1 \mathrm{~mm}$ larger in the stent-assisted coiling group compared with the coiling-alone group (Table 2). The higher complexity of these aneurysms probably explains the higher complication rate.

\section{Antiaggregation}

The day before elective treatment of the aneurysms, we performed a platelet test. If the patient was a responder to clopidogrel and a stent was used during treatment, a daily dose of $75 \mathrm{mg}$ of clopidogrel was given until 6 weeks after the intervention. In case of a nonresponder to clopidogrel, the patient received a loading dose of $180 \mathrm{mg}$ of ticagrelor before treatment and a dose of $90 \mathrm{mg}$ of ticagrelor twice daily for 6 weeks. Wide-neck aneurysms or protruded coils were usually treated afterward by $100 \mathrm{mg}$ of ASA for 6 weeks. Patients treated with a WEB device had to take $100 \mathrm{mg}$ of 
ASA for 6 weeks. ASA was only administrated for 6 months if signs of atherosclerosis had been observed during intervention. Subsequent medication administration was stopped without influencing the long-term outcome on follow-up. Thromboembolic events occurred 5 times under simple antiaggregation and 3 times under double antiaggregation. We found a lower thromoboembolic event rate in double antiaggregation $(n=3 / 78,3.8 \%)$ than in simple antiaggregation $(n=5 / 72,7 \%)$. Double antiaggregation seems to be a safe way to reduce thromboembolic events without increasing the hemorrhagic risk (Table 5). Three thromboembolic events occurred after positive findings on the Multiplate Analyzer test. In 4, no Multiplate Analyzer test was documented in the electronic medical files. These events can probably be prevented by a switch from clopidogrel to ticagrelor.

\section{Treatment Time}

We found a significantly lower total treatment time in the WEB group compared with the coil group or the stent-assisted coiling group (136 versus 155 versus 165 minutes, respectively). One major point seems to be the number of devices used. De Gast et al ${ }^{12}$ concluded that coiling of MCA aneurysms takes considerably more time than other intracranial aneurysms. They described a mean treatment time of 57 minutes without preprocedural diagnostic angiography and anesthesiology procedures. We defined our treatment time as the period from intubation to extubation, including the panangiography, the current treatment, and the postinterventional DynaCT (Siemens). In a clinical setting, these points are relevant for the slot planning in daily activity and explain the great difference between de Gast et $\mathrm{al}^{12}$ and our study.

\section{Reintervention Rate}

We observed a learning curve using the WEB device because we saw a decreasing reintervention rate compared with the increasing number of cases (Fig 3). Behme et $\mathrm{al}^{10}$ found that in 2 years after their first use of a WEB device, the occlusion rate increased to $87.5 \%$ in the 3-month follow-up. Nonetheless, in our cohort, the retreatment rate was significantly higher in the WEB group (21.1\%) compared with the coiling-alone $(2.2 \%)$ or the stentassisted coiling (5.9\%) group. Published data for the reintervention rate of coiled aneurysms range between $4.7 \%{ }^{13}$ and $12.3 \% .{ }^{14}$ One major point outlined in the literature is that in thrombosed or partially thrombosed aneurysms, the WEB device could not achieve contact with the aneurysm wall and therefore posed a high risk of recurrence. The WEB device is probably not feasible for this special subtype of aneurysm. Also, device compaction could induce treatment failure as seen in other endovascular techniques such as coiling.

We found no differences in both groups regarding the rate of thrombotic events. One major problem of comparing the reintervention rate with that in other studies is the subjective classification and experience of the interventionalists. Darflinger et $\mathrm{al}^{15}$ described the differences between reperfusion of an aneurysm and the retreatment. He proposed that only aneurysms that are graded as II or III according to the Raymond-Roy classification should be treated. If $<69 \%$ of the treated aneurysm volume is reopened, then the rupture risk seems to be equal to that in untreated aneurysms. Aneurysms classified as Raymond-Roy I or II, however, might be successfully treated. ${ }^{16}$ Pierot et al ${ }^{17}$ discovered that the recanalization of aneurysms treated by the WEB device was $20.9 \%$, but the reintervention rate was much lower (6.9\%). Further investigation seems to be warranted to clarify treatment success in aneurysms treated with the WEB device.

Our reintervention rate was not higher than the numbers mentioned in the literature. However, in our data, the follow-up period differed significantly between both groups. One reason is that the WEB device was released in 2011 and was only used for the first time in Augsburg in 2012. Naturally, an endovascular reintervention means mental stress for the patient. However, a reintervention by an endovascular technique presents a safe and good way to treat patients. ${ }^{18}$ We found that nearly all reinterventions were completed in 6 months after the first therapy. Most of the studies mention a mean of 8 months after intervention as being the highest risk time. ${ }^{19}$ Additionally, Ferns et $\mathrm{al}^{20}$ reported that a longer follow-up period does not increase the reopening rate or reintervention rate in treated intracranial aneurysms. In our series, $92.3 \%$ of all decisions to retreat an already treated aneurysm were made within 6 months. Thus, a postinterventional angiographic control within 3-6 months seems indispensable.

\section{Limitations}

Our study has several limitations. First, it is a single-center, nonrandomized retrospective cohort. Comparison, especially with clipping, can only be made via published literature. Particularly with regard to the Web group, we observed a clear learning curve, so our data may underestimate the potential of the WEB device in this challenging subgroup of aneurysms. Otherwise in contrast to other studies, ${ }^{3}$ we have a very limited selection bias for endovascular treatment. This shows that a wide variety of complex MCA bifurcation aneurysms can be treated using endovascular means alone.

\section{CONCLUSIONS}

Endovascular treatment of MCA bifurcation aneurysms seems to be a safe option regardless of the aneurysm morphology and vascular anatomy, with low morbidity and mortality rates. The WEB device might have the potential to facilitate treatment of this challenging subtype of aneurysms even further.

Disclosures: Christoph Maurer-UNRELATED: Grants/Grants Pending: MicroVention, Stryker, Comments: educational grants. Ansgar Berlis-UNRELATED: Consulting Fee or Honorarium: proctoring for MicroVention, Medtronic, Stryker, and Sequent Medical; honorarium from Penumbra for lectures; Fees for Participation in Review Activities Such as Data Monitoring Boards, Statistical Analysis, Endpoint Committees, and the Like: CEC Phenox.

\section{REFERENCES}

1. Molyneux A, Kerr R, Stratton I, et al. International Subarachnoid Aneurysm Trial (ISAT) of neurosurgical clipping versus endovascular coiling in 2143 patients with ruptured intracranial aneurysms: a randomised trial. Lancet 2002;360:1267-74 CrossRef Medline

2. Wiebers DO. Unruptured intracranial aneurysms: natural history, clinical outcome, and risks of surgical and endovascular treatment. Lancet 2003;362:103-10 CrossRef Medline

3. Schwartz C, Aster HC, Al-Schameri R, et al. Microsurgical clipping and endovascular treatment of middle cerebral artery aneurysms in 
an interdisciplinary treatment concept: comparison of long-term results. Interv Neuroradiol 2018;24:608-14 CrossRef Medline

4. Nussbaum ES, Madison MT, Goddard JK, et al. Microsurgical treatment of unruptured middle cerebral artery aneurysms: a large, contemporary experience. J Neurosurg 2018:1-7 CrossRef Medline

5. Janssen H, Berlis A, Lutz J, et al. State of practice: endovascular treatment of acute aneurysmal SAH in Germany. AJNR Am J Neuroradiol 2017;38:1574-79 CrossRef Medline

6. Taschner CA, Chapot R, Costalat V, et al. Second-generation hydrogel coils for the endovascular treatment of intracranial aneurysms: a randomized controlled trial. Stroke 2018;49:667-74 CrossRef Medline

7. McDonald JS, McDonald RJ, Fan J, et al. Comparative effectiveness of unruptured cerebral aneurysm therapies: propensity score analysis of clipping versus coiling. Stroke 2013;44:988-94 CrossRef Medline

8. Rodríguez-Hernandez A, Sughrue ME, Akhavan S, et al. Current management of middle cerebral artery aneurysms: surgical results with a "clip first" policy. Neurosurgery 2013;72:415-27 CrossRef Medline

9. Choi JH, Park JE, Kim MJ, et al. Aneurysmal neck clipping as the primary treatment option for both ruptured and unruptured middle cerebral artery aneurysms. J Korean Neurosurg Soc 2016;59: 269-75 CrossRef Medline

10. Behme D, Berlis A, Weber W. Woven EndoBridge intrasaccular flow disrupter for the treatment of ruptured and unruptured wide-neck cerebral aneurysms: report of 55 cases. AJNR Am J Neuroradiol 2015; 36:1501-06 CrossRef Medline

11. Hwang G, Huh W, Lee JS, et al. Standard vs modified antiplatelet preparation for preventing thromboembolic events in patients with high on-treatment platelet reactivity undergoing coil embolization for an unruptured intracranial aneurysm: a randomized clinical trial. JAMA Neurol 2015;72:764-72 CrossRef Medline
12. de Gast AN, Soepboer A, Sluzewski M, et al. How long does it take to coil an intracranial aneurysm? Neuroradiology 2008;50:53-56 CrossRef Medline

13. Cognard C, Weill A, Spelle L, et al. Long-term angiographic follow-up of 169 intracranial berry aneurysms occluded with detachable coils. Radiology 1999;212:348-56 CrossRef Medline

14. Henkes H, Fischer S, Liebig T, et al. Repeated endovascular coil occlusion in $\mathbf{3 5 0}$ of $\mathbf{2 7 5 9}$ intracranial aneurysms: safety and effectiveness aspects. Neurosurgery 2006;58:224-32; discussion 224-32 CrossRef Medline

15. Darflinger R, Thompson LA, Zhang Z, et al. Recurrence, retreatment, and rebleed rates of coiled aneurysms with respect to the Raymond-Roy scale: a meta-analysis. J Neurointerv Surg 2016;8:507-11 CrossRef Medline

16. Johnston SC, Dowd CF, Higashida RT, et al; CARAT Investigators. Predictors of rehemorrhage after treatment of ruptured intracranial aneurysms: the Cerebral Aneurysm Rerupture After Treatment (CARAT) study. Stroke 2008;39120-25 CrossRef Medline

17. Pierot L, Moret J, Barreau X, et al. Safety and efficacy of aneurysm treatment with WEB in the cumulative population of three prospective, multicenter series. J Neurointerv Surg 2018;10:553-59 CrossRef Medline

18. Ries T, Siemonsen S, Thomalla G, et al. Long-term follow-up of cerebral aneurysms after endovascular therapy prediction and outcome of retreatment. AJNR Am J Neuroradiol 2007;28:1755-61 CrossRef Medline

19. Teleb MS, Pandya DJ, Castonguay AC, et al. Safety and predictors of aneurysm retreatment for remnant intracranial aneurysm after initial endovascular embolization. J Neurointerv Surg 2014;6:490-94 CrossRef Medline

20. Ferns SP, Sprengers MES, van Rooij WJ, et al. Coiling of intracranial aneurysms: a systematic review on initial occlusion and reopening and retreatment rates. Stroke 2009;40:e523-29 CrossRef Medline 